SUBJECT AREAS:

REACTION MECHANISMS

MASS SPECTROMETRY

Received

16 September 2013

Accepted

25 November 2013

Published

11 December 2013

Correspondence and requests for materials should be addressed to

Z.P.Z.

(zhangzp0304@

gmail.com); X.R.Z.

(xrzhang@tsinghua.

edu.cn) or Z.O.

(ouyang@purdue.edu)

\title{
Observation of Replacement of Carbon in Benzene with Nitrogen in a Low-Temperature Plasma
}

\author{
Zhiping Zhang' ', Xiaoyun Gong' ${ }^{2}$, Sichun Zhang ${ }^{2}$, Haijun Yang ${ }^{2}$, Youmin Shi ${ }^{2}$, Chengdui Yang ${ }^{2}$, \\ Xinrong Zhang ${ }^{2}$, Xingchuang Xiong ${ }^{3}$, Xiang Fang ${ }^{3} \&$ Zheng Ouyang ${ }^{4}$
}

\begin{abstract}
${ }^{1}$ School of Chemistry and Chemical Engineering, Xi'an Shiyou University, Xi'an 710065 (China), ${ }^{2}$ Department of Chemistry, Tsinghua University, Beijing 100084 (China), ${ }^{3}$ National Institute of Metrology, Beijing 100013 (China), ${ }^{4}$ Weldon School of Biomedical Engineering, Purdue University, West Lafayette, Indiana 47907 (USA)
\end{abstract}

Selective activation of benzene has been mainly limited to the $\mathrm{C}-\mathrm{H}$ activation. Simple replacement of one carbon in benzene with another atom remains unresolved due to the high dissociation energy. Herein, we demonstrate a direct breakage of the particularly strong $\mathrm{C}=\mathrm{C}$ bond in benzene through ion-molecule reaction in a low-temperature plasma, in which one carbon atom was replaced by one atomic nitrogen with the formation of pyridine. The mechanism for the formation of pyridine from benzene has been proposed based on the extensive investigation with tandem mass spectrometry. The reaction pathway also works to other aromatics such as toluene and o-xylene. This finding provides a new avenue for selective conversion of aromatics into nitrogen-containing compounds.

enzene is an extremely stable aromatic ring, and is hardly replaced one carbon atom in $\mathrm{C}=\mathrm{C}$ bond by other heteroatoms without breaking the aromatic ring. Although the interactions between benzene and diverse heteroatoms including $\mathrm{N}^{1-6}, \mathrm{O}^{7-9}, \mathrm{Si}^{10,11}$ and $\mathrm{P}^{12,13}$ have been extensively investigated, there has been little experimental evidence to produce heterocyclic compounds from benzene ${ }^{13}$. The exclusive example on the selective breakage of carbon-carbon bond in benzene can be dated back to two decades ago, in which Muedas et al. ${ }^{13}$ presented an evidence on the insertion of a phosphorus atom into the skeleton of benzene and formation of a seven-membered ring, which was achieved through the reaction with $\mathrm{PI}_{3}$ in an ion-molecule reaction. Recently, Cooks et al. ${ }^{14}$ reported a strategy for the direct insertion of one nitrogen into $\mathrm{C}-\mathrm{C}$ bond of saturated alkanes to form iminium salts via simple one-step reactions involving gas phase ions and high energy plasma processes. Considering the significance of heterocyclic compound directly derived from benzene in chemical industry, it is desirable to have some strategies developed for this reaction. While the reduction of carbon-carbon bond in benzene could be achieved with facilitation by plasma ${ }^{15}$, there has been no report so far on the selective replacement of one carbon atom in benzene with heteroatom.

In this study, we observed that one carbon atom in benzene can be directly replaced with nitrogen atom producing pyridine through ion-molecule reaction in a low-temperature plasma. The formation of pyridine was confirmed with its exact mass measurement, tandem mass spectrometry and isotopic labeling study, and the reaction product was collected and identified via chromatography technique. According to the results from mass spectrometry, the underlying reaction pathway for the pyridine formation from benzene was proposed, in which it involves a carbon replacement with nitrogen-containing species and the ring-opening and closing reactions. Since this process has been regarded as impossible using typical synthesis routes for a long time, this finding paves the way for the direct synthesis of heterocyclic compounds from benzene.

\section{Results}

The experiment was carried out by introducing benzene vapor with air into a low-temperature plasma region (Figure S1). The reaction product was on-line monitored using a high resolution Orbitrap mass spectrometer. Besides the peaks at mass-over-charge ratio $(\mathrm{m} / \mathrm{z}) 94.0651\left(\mathrm{C}_{6} \mathrm{H}_{8} \mathrm{~N}^{+}\right), 110.0600\left(\mathrm{C}_{6} \mathrm{H}_{8} \mathrm{ON}^{+}\right)$and 126.0551 $\left(\mathrm{C}_{6} \mathrm{H}_{8} \mathrm{NO}_{2}^{+}\right)$, the most abundant ionic species observed was $\mathrm{m} / \mathrm{z} 80.0494$ (Figure 1A), which was different from the typical molecular ion of benzene (m/z 78.0469) as shown in Figure S2 in mass spectrometry (MS) analysis ${ }^{16}$. In a previous study under a similar plasma condition but with benzene in helium, ion $[\mathrm{M}+2]^{+}$was observed and was 

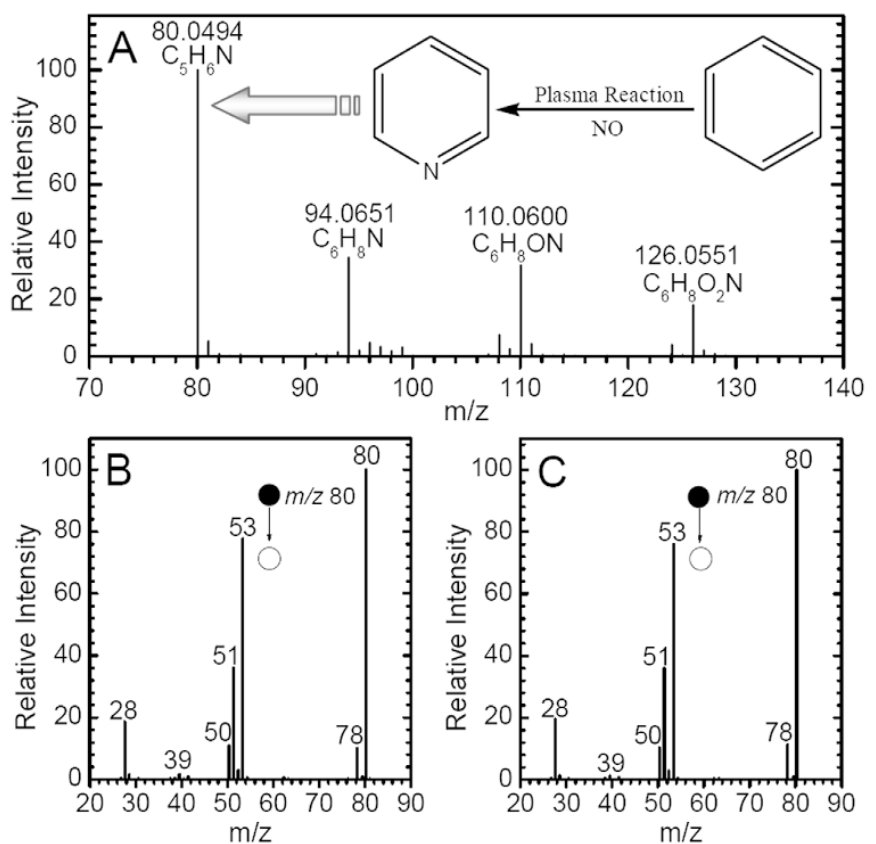

Figure 1 (A) Mass spectrum of the product from the plasma reaction of benzene using a high resolution Exactive Orbitrap mass spectrometry.

(B) Fragmentation pattern of the product $(\mathrm{m} / \mathrm{z} 80)$ from the plasma reaction with benzene. (C) Fragmentation pattern of $\mathrm{m} / \mathrm{z} 80$ from pyridine standard sample using nano-ESI. identified as $\mathrm{C}_{6} \mathrm{H}_{8}{ }^{+}$based on deuterium isotopic labeling experiments $^{15}$. The chemical formula of the ion $\mathrm{m} / \mathrm{z} 80.0494$ observed in this study was assigned as $\mathrm{C}_{5} \mathrm{H}_{6} \mathrm{~N}^{+}$(Figures $\mathrm{S} 3$ and $\mathrm{S} 4$ ). This peak was the most abundant in the spectrum (Figure 1A), which suggests that this reaction was highly efficient in producing this unusual product.

To confirm the chemical structure of the product $\mathrm{C}_{5} \mathrm{H}_{6} \mathrm{~N}^{+}(\mathrm{m} / \mathrm{z}$ 80) generated from benzene, MS/MS analysis was performed and the fragmentation pattern was compared with that from pyridine (analytical standard). As shown in Figure $1 \mathrm{~B}$ and $\mathrm{C}$, both cations $\mathrm{C}_{5} \mathrm{H}_{6} \mathrm{~N}^{+}$ $(\mathrm{m} / \mathrm{z} 80)$ generated from benzene through the plasma reaction and from pyridine standard sample by nano-electrospray ionization (nano-ESI) have identical fragmentation patterns, with fragments of $\mathrm{m} / \mathrm{z} 28\left(\mathrm{CNH}_{2}{ }^{+}\right), 50\left(\mathrm{C}_{4} \mathrm{H}_{2}{ }^{+}\right), 51\left(\mathrm{C}_{4} \mathrm{H}_{3}{ }^{+}\right), 53\left(\mathrm{C}_{4} \mathrm{H}_{5}{ }^{+}\right)$and 78 $\left(\mathrm{C}_{5} \mathrm{NH}_{4}{ }^{+}\right)$observed at similar relative intensities. This result suggests the product $\mathrm{C}_{5} \mathrm{H}_{6} \mathrm{~N}^{+}(\mathrm{m} / \mathrm{z} 80)$ probably has a structure of pyridine. $\mathrm{D}_{6}$-benzene was also used for the plasma reaction and ions at $\mathrm{m} / \mathrm{z}$ 85.0810 and 86.0871 were observed, corresponding to $\mathrm{C}_{5} \mathrm{D}_{5} \mathrm{HN}^{+}$and $\mathrm{C}_{5} \mathrm{D}_{6} \mathrm{~N}^{+}$, respectively (Figures $2 \mathrm{~A}, \mathrm{~S} 5$ and S6). The most abundant ion $\mathrm{C}_{5} \mathrm{D}_{5} \mathrm{HN}^{+}$at $\mathrm{m} / \mathrm{z} 85.0810$ could be attributed to the transfer of a proton from water in air during the reaction. In its MS/MS spectrum, a similar dissociation pathway as those from benzene and pyridine was observed, with fragments of $\mathrm{m} / \mathrm{z} 29\left(\mathrm{CNHD}^{+}\right), 30\left(\mathrm{CND}_{2}{ }^{+}\right), 51$ $\left(\mathrm{C}_{4} \mathrm{HD}^{+}\right), 52\left(\mathrm{C}_{4} \mathrm{D}_{2}^{+}\right), 53\left(\mathrm{C}_{4} \mathrm{HD}_{2}^{+}\right), 54\left(\mathrm{C}_{4} \mathrm{D}_{3}^{+}\right), 57\left(\mathrm{C}_{4} \mathrm{HD}_{4}^{+}\right), 58$ $\left(\mathrm{C}_{4} \mathrm{D}_{5}{ }^{+}\right), 81\left(\mathrm{C}_{5} \mathrm{NHD}_{3}{ }^{+}\right)$and $82\left(\mathrm{C}_{5} \mathrm{ND}_{4}^{+}\right)$(Figures $2 \mathrm{~B}$ and $\mathrm{S} 6 \mathrm{D}$ ), confirming the occurrence of conversion from benzene to pyridine. Further convinced evidence on the production of pyridine from benzene has been obtained by gas chromatography/mass spectrometry (GC/MS) analyses. When pure benzene was used for the analysis, no pyridine peak was observed in the chromatogram (Figure 2C). However, the retention peak of pyridine appeared at $3.44 \mathrm{~min}$ for the collected product from the plasma reaction of
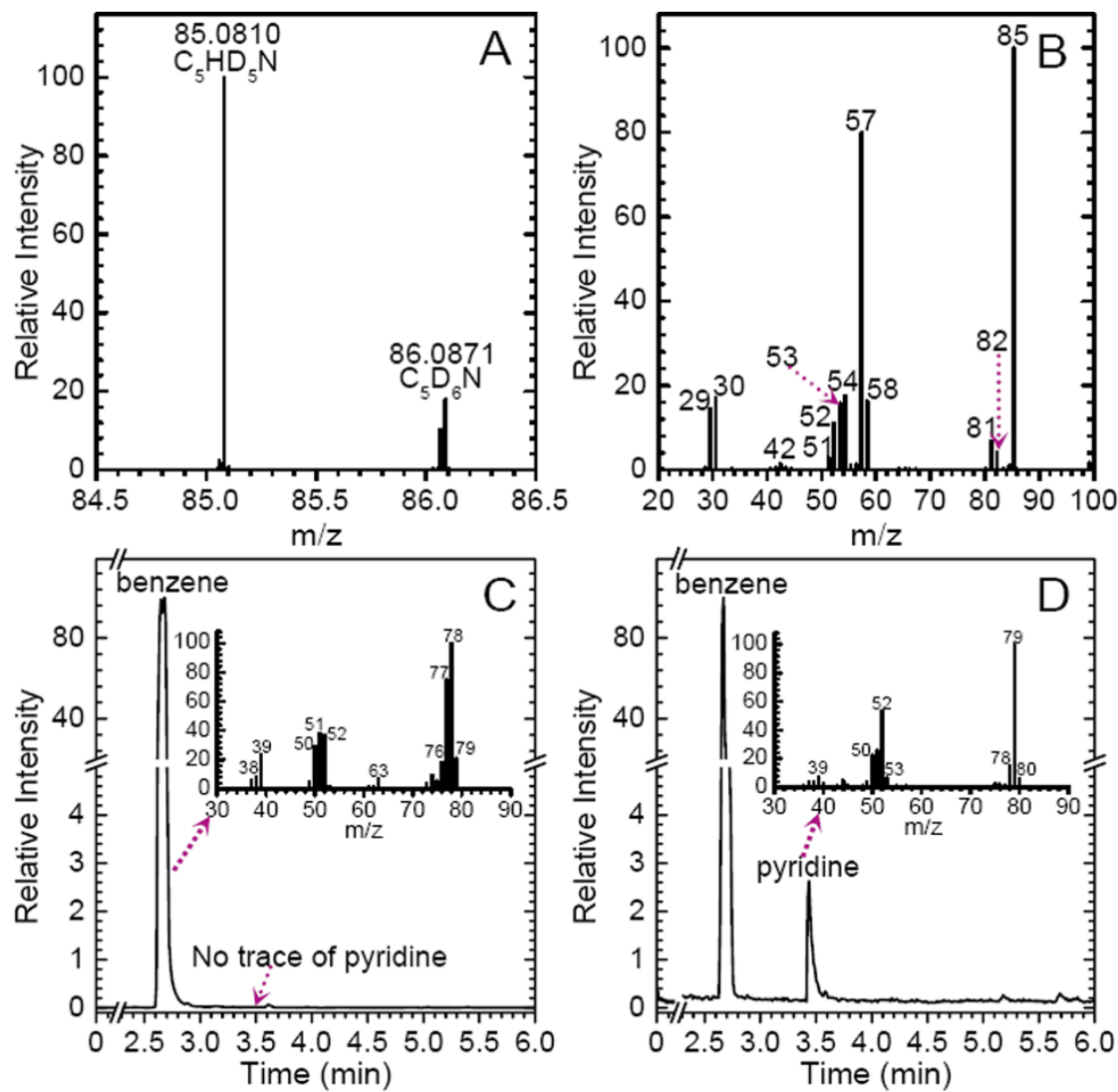

Figure $2 \mid$ (A) The mass spectrum of the product from the plasma reaction with $\mathrm{D}_{6}$-benzene. (B) Fragmentation pattern of the molecular ion ( $\mathrm{m} / \mathrm{z}$ 85) generated by the plasma reaction of $\mathrm{D}_{6}$-benzene. (C) GC/MS chromatogram of pure benzene. (D) GC/MS chromatogram of the product from benzene. (Note: The insets in (C) and (D) are the corresponding mass spectra of the marked peaks.) 

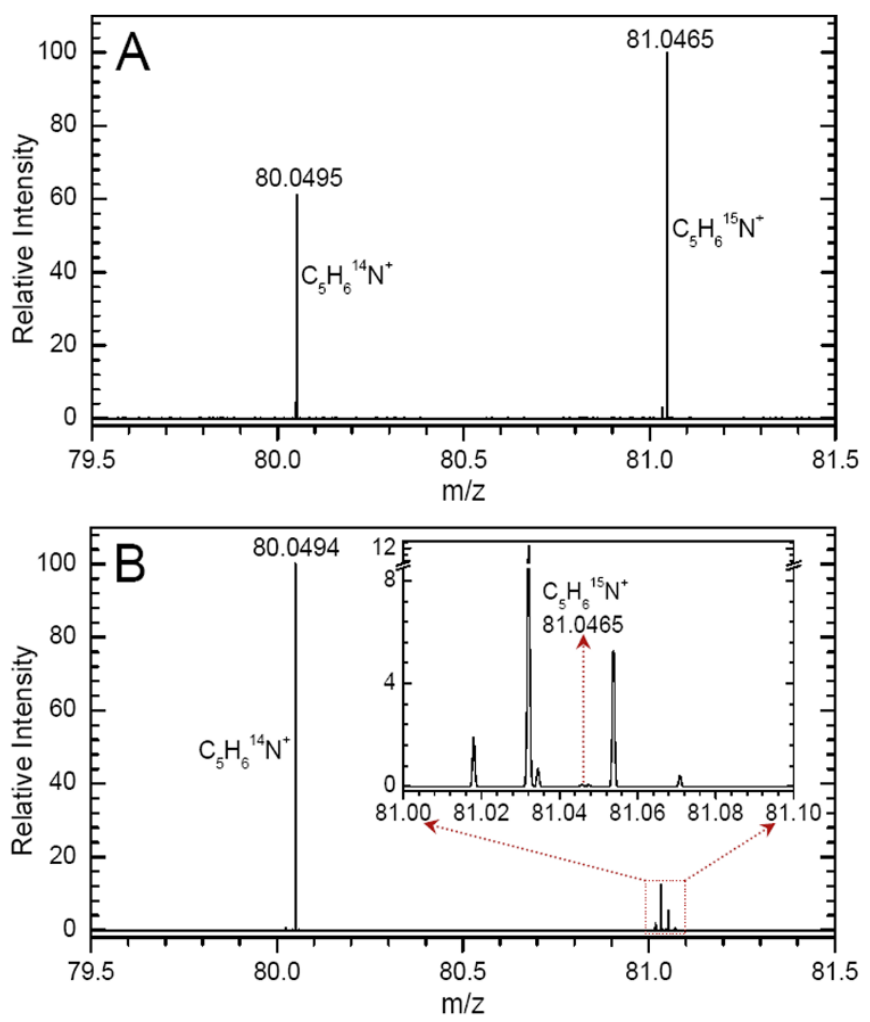

Figure 3 Comparison of the peak intensity of $\mathrm{C}_{5} \mathrm{H}_{6}{ }^{15} \mathrm{~N}$ from the respective reaction of benzene and $\mathrm{NO}$ and ${ }^{15} \mathrm{NO}$. Mass spectrum of (A) the reaction product between benzene and ${ }^{15} \mathrm{~N}$ containing species such as ${ }^{15} \mathrm{NO}$ generated from the discharge reaction of $\mathrm{O}_{2}$ and ${ }^{15} \mathrm{NH}_{3}$ and (B) the general reaction product obtained from benzene and $\mathrm{NO}$ (the inset is the close-up image of the marked section). Note: ${ }^{15} \mathrm{NH}_{3}$ was generated by addition of $0.3349 \mathrm{~g}^{15} \mathrm{NH}_{4} \mathrm{Cl}$ into $2 \mathrm{~mL}$ of $1.0 \mathrm{~mol} \mathrm{~L}^{-1} \mathrm{NaOH}$ solution.

benzene (Figure 2D) by using the apparatus as shown in Figure S7. This is in good agreement with the retention behavior of pyridine standard (Figure S8).

In an effort of identifying the source of nitrogen atom involved in the replacement of the carbon from benzene, different gases, including air, pure $\mathrm{N}_{2}$, and the mixture of $\mathrm{N}_{2}$ and $\mathrm{NO}(99: 1, \mathrm{v} / \mathrm{v})$, were used for the plasma reaction. The results shown in Figure $\mathrm{S} 9$ clearly demonstrate that NO-containing gas more favors the generation of pyridine than air and pure $\mathrm{N}_{2}$ in this reaction. ${ }^{15} \mathrm{NO}$ was then added into the reaction for tracing the nitrogen source via isotope ratio analysis. After a reaction period of $30 \mathrm{~min}$, the liquid sample was analyzed using an Orbitrap mass spectrometer. As expected, the peak intensity of ${ }^{15} \mathrm{~N}$-labeled cation $\left(\mathrm{C}_{5} \mathrm{H}_{6}{ }^{15} \mathrm{~N}^{+}\right)$sharply increased, and the ratio between ${ }^{15} \mathrm{~N}$-labeled cation $\left(\mathrm{C}_{5} \mathrm{H}_{6}{ }^{15} \mathrm{~N}^{+}\right)$and $\mathrm{C}_{5} \mathrm{H}_{6}{ }^{14} \mathrm{~N}^{+}$was 1.53 (Figure $3 \mathrm{~A}$ ). On the contrary, the peak intensity ratio was only 0.05 for the reaction using NO (Figure $3 \mathrm{~B}$ ). This provides a direct evidence that the pyridine product was generated from the reaction with exogenous nitrogen-containing species rather than contaminants in the original benzene solvent.

\section{Discussion}

Besides the dielectric barrier discharge apparatus (Figure S1), other reaction systems such as paper- or needle-based discharge (Figure S10) were also used to investigate the discharge reaction products of benzene at atmospheric pressure without any other auxiliary gases. It is interesting that the same reaction product patterns were observed (Data not shown). These results demonstrate that the production of $\mathrm{C}_{6} \mathrm{H}_{8} \mathrm{~N}^{+}$under the discharge of benzene is a general case.
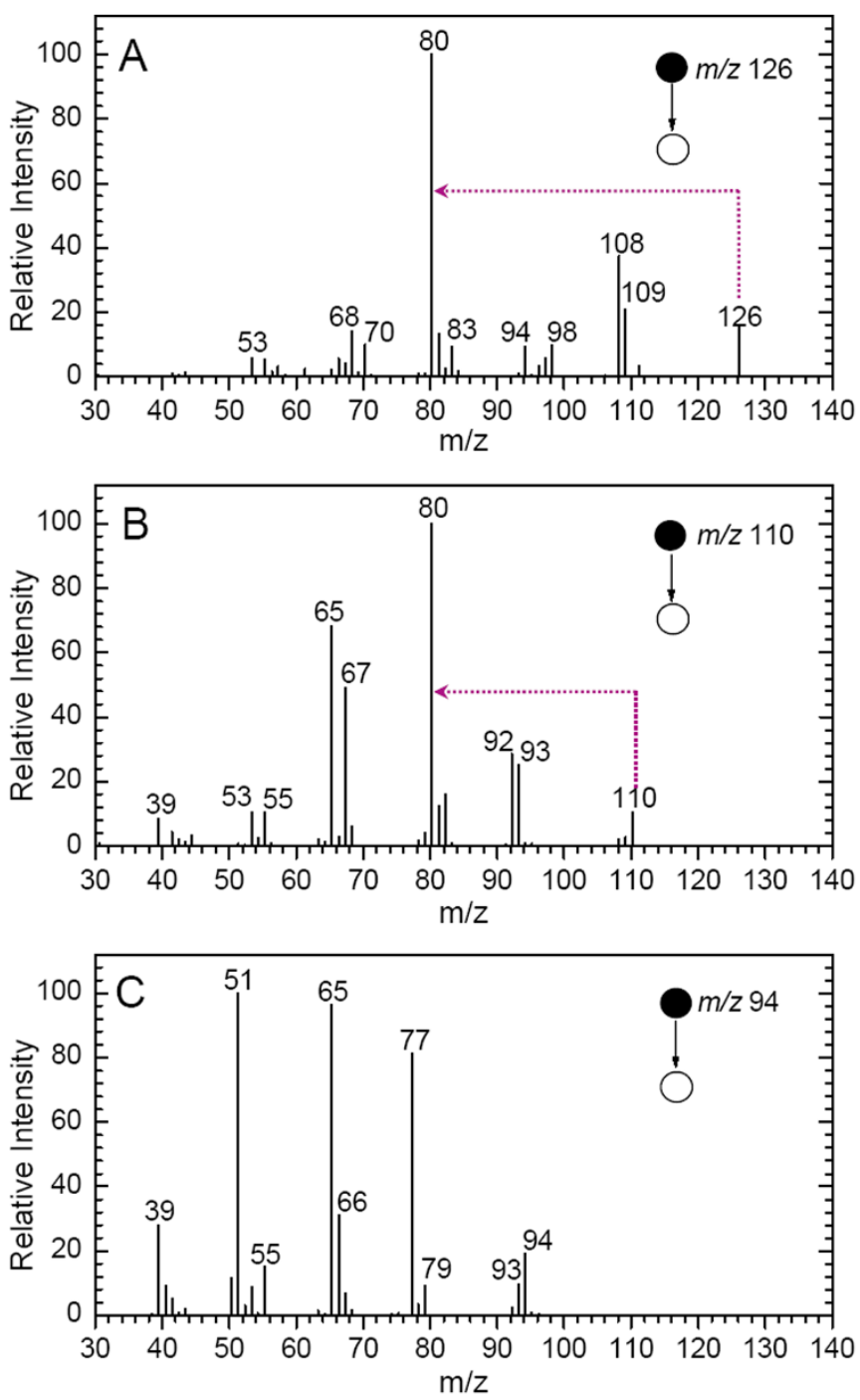

Figure $4 \mid \mathrm{MS} / \mathrm{MS}$ spectra of the peaks at (A) $\mathrm{m} / \mathrm{z} 126$, (B) $\mathrm{m} / \mathrm{z} 110$ and (C) $\mathrm{m} / \mathrm{z} 94$ produced from the plasma reaction of benzene.

To give some insights into the formation of $\mathrm{C}_{5} \mathrm{H}_{6} \mathrm{~N}^{+}$from benzene, efforts were carried out to its origin. As shown in Figure 1, besides the peak $\mathrm{C}_{5} \mathrm{H}_{6} \mathrm{~N}^{+}$at $\mathrm{m} / \mathrm{z}$ 80.0494, three other abundant peaks, assigned to $\mathrm{C}_{6} \mathrm{H}_{8} \mathrm{~N}^{+}\left(\mathrm{m} / \mathrm{z}\right.$ 94.0651), $\mathrm{C}_{6} \mathrm{H}_{8} \mathrm{ON}^{+}(\mathrm{m} / \mathrm{z}$ $110.0600)$ and $\mathrm{C}_{6} \mathrm{H}_{8} \mathrm{NO}_{2}{ }^{+}(\mathrm{m} / \mathrm{z} 126.0551)$, were also observed in the mass spectrum. However, the intensity for these peaks became much lower for the collected reaction products (Figure S11). Further MS/MS analysis of these species showed that $\mathrm{C}_{5} \mathrm{H}_{6} \mathrm{~N}^{+}$can be originated as the most abundant species from $\mathrm{C}_{6} \mathrm{H}_{8} \mathrm{O}_{2} \mathrm{~N}^{+}(\mathrm{m} / \mathrm{z} 126)$ and $\mathrm{C}_{6} \mathrm{H}_{8} \mathrm{ON}^{+}(\mathrm{m} / \mathrm{z} 110)$ through loss of one molecule $\mathrm{H}_{2} \mathrm{O}$ and $\mathrm{CO}$ or $\mathrm{C}$ group by collision induced dissociation (CID) as shown in Figure 4. For the ion $\mathrm{m} / \mathrm{z} 94$, no direct experimental results were found to be related with the production of $\mathrm{m} / \mathrm{z} 80\left(\mathrm{C}_{5} \mathrm{H}_{6} \mathrm{~N}^{+}\right)$as shown in Figure $4 \mathrm{C}$. Also, the component of $\mathrm{m} / \mathrm{z} 94$ varied from $\mathrm{C}_{6} \mathrm{H}_{8} \mathrm{~N}$ to $\mathrm{C}_{6} \mathrm{H}_{6} \mathrm{O}$ with reaction time (Figures $\mathrm{S} 12$ ), and their possible formation mechanisms were suggested as Scheme S1. From Figure S12, it can be seen that the formation of $\mathrm{C}_{6} \mathrm{H}_{8} \mathrm{~N}$ and $\mathrm{C}_{6} \mathrm{H}_{6} \mathrm{O}$ should be one pair of competing reactions. Further detailed investigation is needed to elucidate the source and conversion of $\mathrm{C}_{6} \mathrm{H}_{8} \mathrm{~N}$ to $\mathrm{C}_{6} \mathrm{H}_{6} \mathrm{O}(\mathrm{m} / \mathrm{z}$ 94) as well as $\mathrm{C}_{6} \mathrm{H}_{8} \mathrm{ON}^{+}(\mathrm{m} / \mathrm{z} 110)$ and $\mathrm{C}_{6} \mathrm{H}_{8} \mathrm{O}_{2} \mathrm{~N}^{+}(\mathrm{m} / \mathrm{z} 126)$.

According to the experimental results, a possible mechanism for pyridine formation from benzene is suggested in Figure 5a. The intermediate $\mathrm{C}_{6} \mathrm{H}_{8} \mathrm{O}_{2} \mathrm{~N}^{+}$with $\mathrm{m} / \mathrm{z} 126$ (Figure $4 \mathrm{~A}$ ) is first formed through the interaction between benzene and $\mathrm{NO}^{+}, \mathrm{H}_{2} \mathrm{O}$ in air or 


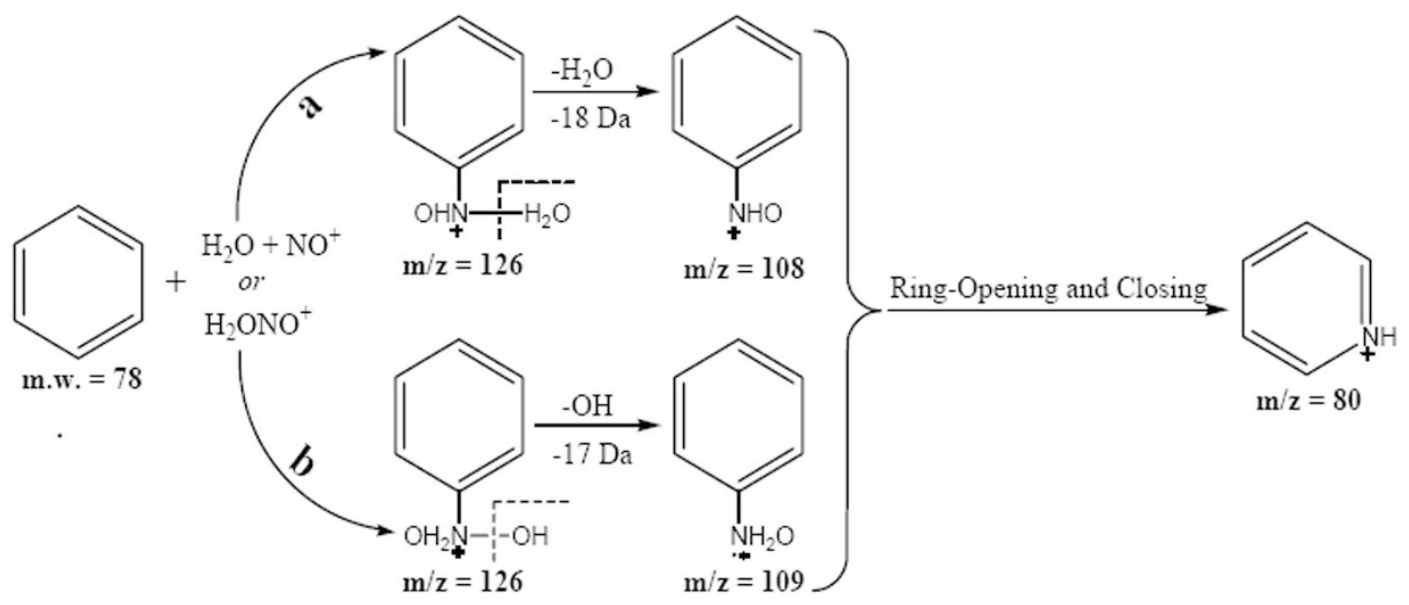

Figure $5 \mid$ The proposed possible formation mechanism of pyridine from benzene.

$\mathrm{H}_{2} \mathrm{ONO}^{+}$, probably derived from a three body dissociation of $\mathrm{NO}^{+}$, $\mathrm{H}_{2} \mathrm{O}$ in air and neutral molecules ${ }^{2,6}$. The rapid loss of $\mathrm{H}_{2} \mathrm{O}$ molecule ${ }^{17,18}$ from $\mathrm{C}_{6} \mathrm{H}_{8} \mathrm{O}_{2} \mathrm{~N}^{+}$results in the production of $\mathrm{C}_{6} \mathrm{H}_{5} \mathrm{NHO}^{+}$ $(\mathrm{m} / \mathrm{z} 108)^{19-22}$, followed by ring- opening and closing reactions with formation of $\mathrm{C}_{5} \mathrm{H}_{6} \mathrm{~N}^{+}(\mathrm{m} / \mathrm{z} 80)$. In addition to this proposed pathway (Figure 5a), other similar mechanism (Figure 5b) might simultaneously undergo due to the existence of the isomers ${ }^{23,24}$. For instance, the peak at $\mathrm{m} / \mathrm{z} 109$ (Figure $4 \mathrm{~A}$ ) could be attributed to the loss of $\mathrm{OH}$ group from the isomeric species of $\mathrm{C}_{6} \mathrm{H}_{5} \mathrm{NH}_{2} \mathrm{OOH}^{+}$(m/z 126), followed by formation of $\mathrm{C}_{5} \mathrm{NH}_{6}{ }^{+}$. The suggested schemes agree well with the formation of pyridine from $\mathrm{m} / \mathrm{z} 110 \mathrm{C}_{6} \mathrm{H}_{8} \mathrm{ON}^{+}$(Figure $4 \mathrm{~B}$ ) as well as the corresponding isotopically labeled products from $\mathrm{D}_{6^{-}}$ benzene (Figures S13-S14).

The reaction pathway also works to other aromatics such as toluene (Figures S15-S21 and Schemes S2-S3) and $o$-xylene (Figure S22). The occurrence of conversion from toluene to 3-picoline based on extensive investigation, as given in the supplementary material, supports that it is generally applicable to perform a direct replacement of one carbon atom in benzene related aromatics with nitrogen atom in the plasma reaction. Due to the limit of the experiment results on the reaction intermediates, there may be other processes leading to the observed products.

In summary, a reaction pathway for the replacement of one carbon atom in benzene with atomic nitrogen, leading to the generation of nitrogen-heterocyclic compounds, was observed in a plasma process. We anticipate the reaction pathway described herein open a door to produce a wide variety of hetero-rings using aromatics as the starting materials.

\section{Methods}

On-line monitoring the reaction product. The isotopically labeled $\mathrm{D}_{6}$-benzene and $\mathrm{D}_{8}$-toluene (99.96 atom\% D), as well as pyridine, 2-picoline, 3-picoline, 4-picoline, and $o$-xylene, were purchased from Sigma-Aldrich (St. Louis, MO). The used benzene and toluene (Beijing Chemical Works, Beijing, China) were chromatographic grade. The isotopically labeled ${ }^{15} \mathrm{NH}_{4} \mathrm{Cl}(>98$ atom\% N) was purchased from Shanghai Engineering Research Center of Stable Isotope (Shanghai, China). All chemicals were used as received. For on-line monitoring the products from the plasma reaction of benzene, $\mathrm{D}_{6}$-benzene, toluene, $\mathrm{D}_{8}$-toluene and $o$-xylene, the experiments were carried out on a plasma reaction chamber (Figure $\mathrm{S} 1$ ) in an air, nitrogen $\left(\mathrm{N}_{2}\right)$ or nitric oxide (NO) atmosphere. Due to the strong toxicity of NO, it was balanced with $99 \%$ nitrogen gas $\left(\mathrm{N}_{2}\right)$. The plasma reaction was carried out in a quartz tube (O.D.: $4.0 \mathrm{~mm}$, I.D.: $3.0 \mathrm{~mm}$, and length: $4.0 \mathrm{~cm}$ ) with one stainless steel electrode inside and the other one touching the outside of the tube. The gas flow rate was maintained at $0.3 \mathrm{~L} \cdot \mathrm{min}^{-1}$. The plasma reaction was controlled with a custom-built $5 \mathrm{~W}$ alternating current $(\mathrm{AC})$ power supply $\left(2.5 \mathrm{kV}_{\mathrm{p}-\mathrm{p}}\right.$ with a frequency of $\left.3.0 \mathrm{kHz}\right)$.

Sample collection. For collecting the plasma reaction product, the apparatus as shown in Figure S7 was used. A 5 W AC power supply, as described above, was applied on a surface dielectric barrier discharge electrode for the plasma reaction. The reaction gas flow rate was maintained at $0.15 \mathrm{~L} \cdot \mathrm{min}^{-1}$, and the reaction temperature was kept at the room temperature. The collected sample was used for analysis without pretreatment unless explicitly indicated otherwise.

Mass spectrometry analysis. A Thermo Scientific Exactive Orbitrap mass spectrometer in a high-resolution mass measurement mode was employed to assign the composition of the resulting products. A TSQ Quantum Access Max (Thermo Scientific, San Jose, CA), operated in the selected reaction monitoring (SRM) mode, was used, and the specific product ions produced by collision-induced dissociation (CID) were monitored. The Xcalibur software was used for control of the TSQ Quantum Access Max MS system and data acquisition. Argon gas (99.995\% purity) was used as collision gas. The temperature for MS inlet capillary was $300^{\circ} \mathrm{C}$.

GC-MS analysis. The GC-MS analysis was completed on a TRACE GC-DSQ (Thermo Fisher Scientific, San Jose, CA) equipped with an AB-5MS capillary column $(30 \mathrm{~m} \times 0.25 \mathrm{~mm}$ i.d. $\times 0.25 \mu \mathrm{m})$. The analysis of the collected sample was operated in a split mode $(50: 1)$. High purity helium was used as carrier gas, and the flow rate was $1.0 \mathrm{~mL} \cdot \mathrm{min}^{-1}$; injector temperature: $250^{\circ} \mathrm{C}$; detector temperature: $250^{\circ} \mathrm{C}$; column temperature: $60^{\circ} \mathrm{C}$ for $2 \mathrm{~min}$ to $300^{\circ} \mathrm{C}$ at $10^{\circ} \mathrm{C} \cdot \mathrm{min}^{-1}$; mass spectrometry scan mode: Full scan; Mass range: $m / z$ 30-650; electron impact: $70 \mathrm{eV}$. Xcalibur 2.0 software (Thermo Fisher Scientific Corp., San Jose, CA) was used for instrument control and data acquisition.

1. Di Stefano, M. et al. Experimental and theoretical investigation of the production of cations containing $\mathrm{C}-\mathrm{N}$ bonds in the reaction of benzene with atomic nitrogen ions. J. Chem. Phys. 119, 1978-1985 (2003).

2. Skokov, S. \& Wheeler, R. A. Oxidative aromatic substitutions: Hartree-Fock/ density functional and ab initio molecular orbital studies of benzene and toluene nitrosation. J Phys. Chem. A 103, 4261-4269 (1999).

3. Giordana, A. et al. The reaction of $\mathrm{N}_{2} \mathrm{O}$ with phenylium ions $\mathrm{C}_{6}(\mathrm{H}, \mathrm{D})_{5}{ }^{+}$: An integrated experimental and theoretical mechanistic study. J. Chem. Phys. 131, (2009).

4. Di Stefano, M., Rosi, M., Sgamellotti, A. \& Negri, F. Reactions of $\mathrm{N}^{+}$ions with benzene: a theoretical study on the $\mathrm{C}_{6} \mathrm{NH}_{6}{ }^{+}$potential energy surface. Chem. Phys. 302, 295-308 (2004).

5. Ascenzi, D., Franceschi, P., Freegarde, T. G. M., Tosi, P. \& Bassi, D. C-N bond formation in the reaction of nitrogen ions $\mathrm{N}^{+}$with benzene molecules. Chem. Phys. Lett. 346, 35-40 (2001).

6. Smith, D., Wang, T. S. \& Spanel, P. A SIFT study of the reactions of $\mathrm{H}_{2} \mathrm{ONO}^{+}$ions with several types of organic molecules. Int. J. Mass Spectrom. 230, 1-9 (2003).

7. Niwa, S. et al. A one-step conversion of benzene to phenol with a palladium membrane. Science 295, 105-107 (2002).

8. Ascenzi, D., Franceschi, P., Guella, G. \& Tosi, P. Phenol production in benzene/air plasmas at atmospheric pressure. Role of radical and ionic routes. J. Phys. Chem. A 110, 7841-7847 (2006).

9. Rosso, J. A., Bertolotti, S. G., Braun, A. M., Martire, D. O. \& Gonzalez, M. C. Reactions of carbon dioxide radical anion with substituted benzenes. J. Phys. Org. Chem. 14, 300-309 (2001).

10. Srinivas, R., Hrusak, J., Sulzle, D., Bohme, D. K. \& Schwarz, H. Experimental and theoretical characterization of isomeric adduct ions of $\mathrm{Si}^{\cdot+}$ and benzene and their neutral counterparts. J. Am. Chem. Soc. 114, 2802-2806 (1992).

11. Allen, W. N. \& Lampe, F. W. Ion-molecule reaction in monosilane-benzene mixtures-long-lived collision complexes. J. Am. Chem. Soc. 99, 2943-2948 (1977).

12. Keck, H., Kuchen, W., Terlouw, J. K. \& Tommes, P. Does phenylphosphinidene exist? Mass spectrometric generation and characterization of Ph-P. Phosphorus, Sulfur Silicon Relat. Elem. 149, 23-28 (1999). 
13. Muedas, C. A., Schroder, D., Sulzle, D. \& Schwarz, H. Insertion of phosphorous into the $\mathrm{C}-\mathrm{C}$ bond of benzene as observed by collision-mass spectrometry. J. Am. Chem. Soc. 114, 7582-7584 (1992).

14. Li, G., Li, X., Ouyang, Z. \& Cooks, R. G. Carbon-Carbon Bond Activation in Saturated Hydrocarbons by Field-Assisted Nitrogen Fixation. Angew. Chem. Int. Edit. 52, 1040-1043 (2013).

15. Na, N., Xia, Y., Zhu, Z., Zhang, X. \& Cooks, R. G. Birch reduction of benzene in a low-temperature plasma. Angew. Chem. Int. Edit. 48, 2017-2019 (2009).

16. Badjagbo, K., Picard, P., Moore, S. \& Sauvé, S. Direct atmospheric pressure chemical ionization-tandem mass spectrometry for the continuous real-time trace analysis of benzene, toluene, ethylbenzene, and xylenes in ambient air. J. Am. Soc. Mass Spectrom. 20, 829-836 (2009).

17. Turney, T. A. \& Wright, G. A. Nitrous acid and nitrosation. Chem. Rev. 59, 497-513 (1959).

18. Williams, D. L. H. in Advances in Physical Organic Chemistry Vol. Volume 19 (eds Gold, V. \& Bethell, D.) 381-428 (Academic Press, 1983).

19. Reents, W. D. \& Freiser, B. S. Gas-phase nitrosation of benzene. Implications for solution electrophilic aromatic substitution reactions. J. Am. Chem. Soc. 102 271-276 (1980).

20. Hubig, S. M. \& Kochi, J. K. Direct observation of the wheland intermediate in electrophilic aromatic substitution. Reversible formation of nitrosoarenium cations. J. Am. Chem. Soc. 122, 8279-8288 (2000).

21. Gwaltney, S. R., Rosokha, S. V., Head-Gordon, M. \& Kochi, J. K. Charge-transfer mechanism for wlectrophilic aromatic nitration and nitrosation via the convergence of (ab Initio) molecular-orbital and Marcus-Hush theories with experiments. J. Am. Chem. Soc. 125, 3273-3283 (2003).

22. Chiavarino, B. et al. $\pi$-complex structure of gaseous benzene-NO cations assayed by IR multiple photon dissociation spectroscopy. J. Am. Chem. Soc. 128 , 12553-12561 (2006)

23. Cacace, F., Attina, M., De Petris, G. \& Speranza, M. Protonated nitric acid. Structure and relative stability of isomeric $\mathrm{H}_{2} \mathrm{NO}_{3}{ }^{+}$ions in the gas phase. J. Am. Chem. Soc. 112, 1014-1018 (1990).

24. De Petris, G., Di Marzio, A. \& Grandinetti, F. $\mathrm{H}_{2} \mathrm{NO}_{2}{ }^{+}$ions in the gas phase: a mass spectrometric and post-SCF ab initio study. J. Phys. Chem. 95, 9782-9787 (1991).

\section{Acknowledgments}

The authors thank Y. Ren and Profs. R.G. Cooks and Y. Xia at Purdue University, Profs. H. Fu and C.J. Xi at Tsinghua University, Prof. Z.X. Nie in the Institute of Chemistry, Chinese Academy of Sciences, and Dr. C.X. Liu at Research Center for Eco-Environmental Sciences, Chinese Academy of Sciences for helpful discussion. This research was supported by the National Natural Science Foundation of China (No. 21205093 and No. 21027013), Ministry of Science and Technology of China (No. 2011YQ09000503), Natural Science Basic Research Plan in Shaanxi Province of China (No. 2012JQ2014), and National Science Foundation of the United States (CHE 0847205).

\section{Author contributions}

Z.Z., Z.O. and X.Z. supervised the project. Z.Z., S.Z., H.Y., X.Z., X.F. and Z.O. conceived and designed the experiments. Z.Z., X.G., C.Y., Y.S. and X.X. performed the experiments. Z.Z., Z.O. and X.Z. wrote the paper and analyzed the data. All authors discussed the results and commented on the manuscript.

\section{Additional information}

Supplementary information accompanies this paper at http://www.nature.com/ scientificreports

Competing financial interests: The authors declare no competing financial interests. How to cite this article: Zhang, Z.P. et al. Observation of Replacement of Carbon in Benzene with Nitrogen in a Low-Temperature Plasma. Sci. Rep. 3, 3481; DOI:10.1038/ srep03481 (2013).

(c) (i) $(-)$ This work is licensed under a Creative Commons Attribution-

BY NC ND NonCommercial-NoDerivs 3.0 Unported license. To view a copy of this license, visit http://creativecommons.org/licenses/by-nc-nd/3.0 